\title{
MAPEAMENTO E AVALIAÇÃO DA QUALIDADE DAS PASTAGENS CULTIVADAS NO TRIÂNGULO MINEIRO A PARTIR DE IMAGENS OLI/LANDSAT-8
}

\author{
Jorge Luís Silva Brito \\ Universidade Federal de Uberlândia, Instituto de Geografia, Uberlândia, MG, Brasil \\ jbrito@ufu.br \\ Roberto Rosa \\ Universidade Federal de Uberlândia, Instituto de Geografia, Uberlândia, MG, Brasil \\ rrosa@ufu.br \\ Vanderlei de Oliveira Ferreira \\ Universidade Federal de Uberlândia, Instituto de Geografia, Uberlândia, MG, Brasil \\ vanderlei.ferreira@ufu.br \\ Eleusa Fátima de Lima \\ Universidade Federal de Uberlândia, Instituto de Geografia, Uberlândia, MG, Brasil \\ eleusa@ufu.br \\ Mirna Karla Amorim da Silva
Universidade Federal de Uberlândia, Instituto de Geografia, Monte Carmelo, MG, Brasil
mirnakarla@ufu.br
}

\begin{abstract}
RESUMO
O objetivo deste trabalho foi mapear e avaliar a qualidade das pastagens na região do Triângulo Mineiro, oeste de Minas Gerais, utilizando as imagens do sensor OLI do satélite Landsat-8, bandas 3, 4 e 5. O processamento digital das imagens foi realizado no software ENVI 5.0. As áreas de pastagens foram delimitadas pelo método de edição vetorial em tela do computador atualizando os dados do mapa de uso da terra do projeto TerraClass, utilizando a composição colorida 5R4G3B. A qualidade das pastagens foi mapeada por meio do índice de vegetação EVI2, derivado das imagens OLI/Landsat-8, com apoio de trabalho de campo.. Os resultados indicaram que as pastagens ocupavam, em 2015, uma área de 24.184,65 km², correspondendo a 45,02\% das terras do Triângulo Mineiro. A classificação dos tipos de pastagem, a partir do índice de vegetação EVI2, indicou que $30,78 \%$ das pastagens do Triângulo Mineiro são de boa qualidade, portanto, não degradadas, enquanto $69,22 \%$ apresentam algum grau de degradação, sendo que $34,61 \%$ foram classificadas como levemente degradadas, $21,83 \%$ como moderadamente degradadas e $12,78 \%$ como fortemente degradadas.
\end{abstract}

Palavras-chave: Monitoramento de pastagens. Imagens biofísicas. Classificação de imagens. Uso da terra. EVI2.

\section{MAPPING AND EVALUATION OF THE QUALITY OF PASTURES CULTIVATED IN THE TRIANGULO MINEIRO USING OLI/LANDSAT-8 IMAGES}

\begin{abstract}
ABSTRAC
The goal of this paper was to mapping and evaluate the quality of the pastures in the Triangulo Mineiro region, western of Minas Gerais State, using OLI sensor images from the Landsat- 8 satellite, bands 3,4 and 5 . The digital image processing was performed with the software ENVI, version 5.0. Grassland areas were delimited by the on-screen vector edition method updating the land use map of TerraClass project, using the 5R4G3B color composition. The grasslands quality was mapped using the EVI2 vegetation index, derived from OLI / Landsat-8 images. The results indicated that pastures occupied, in 2015, an area
\end{abstract}


of $24,184.65 \mathrm{~km}^{2}$, corresponding to $45.02 \%$ of the lands of the Triangulo Mineiro. The classification of pastures types, based on the EVI2 vegetation index, indicated that $30.78 \%$ of the pastures of the Triangulo Mineiro have good quality and therefore not degraded, while $69.22 \%$ have some degree of degradation, with $34,61 \%$ were classified as mildly degraded, $21.83 \%$ as moderately degraded and $12.78 \%$ as heavily degraded.

Keywords: Pasture monitoring; biohysical images; image classification; land use; EVI2.

\section{INTRODUÇÃO}

O Brasil possui o maior rebanho bovino no mundo e é o segundo maior exportador e o segundo maior produtor de carne bovina do mundo (IBGE, 2015). Segundo Peron e Evangelista (2004), 80\% dos 50 a 60 milhões de hectares de pastagens cultivadas no Brasil Central encontram-se em algum estado de degradação, ou seja, em processo evolutivo de perda de vigor, sem possibilidade de recuperação natural e incapazes de sustentar os níveis de produção e qualidade exigidos pelos animais, bem como de superar os efeitos nocivos de pragas, doenças e plantas invasoras. As perdas econômicas e ambientais oriundas de pastagens degradadas indicam a necessidade de se identificar e monitorar condições de produtividade das pastagens ao longo do tempo.

O uso indiscriminado das áreas de pastagens com elevada carga animal e a falta de correção e fertilização dos solos impôs um processo de extrativismo, pela exportação do produto animal, condicionado a perda da capacidade produtiva das pastagens. A degradação de pastagens é entendida como um processo evolutivo de perda de vigor, produtividade e capacidade de recuperação natural, tornando-as susceptíveis aos efeitos nocivos de pragas, doenças e plantas invasoras, culminando com a degradação avançada dos recursos naturais em razão de manejos inadequados (MACEDO e ZIMMER, 1993).

A definição de critérios para a avaliação do estágio de degradação das pastagens cultivadas é tarefa difícil, tanto em vista da diversidade das espécies, quanto em relação das características morfológicas e dos ecossistemas em que são cultivadas.

Estudos têm demonstrado o potencial do uso de imagens de satélite associadas aos índices de vegetação para a caracterização, discriminação e estudo da porcentagem de cobertura verde e biomassa de pastagens cultivadas no bioma Cerrado (SANO et al., 2010; FERREIRA et al., 2013; ANJOS et al., 2013).

Na região do Triângulo Mineiro, oeste de Minas Gerais, as pastagens cultivadas são a classe de cobertura de terras mais representativa, de acordo com o mapeamento de cobertura vegetal natural e antrópica dos biomas brasileiros de 2002 (BRITO e PRUDENTE, 2005; SANO et al., 2010; BRASIL, 2015; BRITO e REIS, 2012).

O objetivo geral da pesquisa foi mapear e definir critérios de níveis de degradação das pastagens na região do Triângulo Mineiro a partir de dados de campo e imagens de satélite. Para alcançar esse objetivo, foram definidos os seguintes objetivos específicos:

1) Obter imagens das áreas amostrais: imagens do sensor $O L /$ do satélite Landsat-8, com resolução espacial de 25 metros;

2) Visitar em campo um conjunto de polígonos de pastagem com variados níveis de degradação;

3) Classificar as pastagens de acordo com o nível de degradação a partir dos dados de campo e do índice de vegetação EVI2, derivado das imagens OLI/Landsat-8.

\section{MATERIAIS E MÉTODOS CARACTERIZAÇÃO DA ÁREA}

A área da pesquisa está localizada no Triângulo Mineiro, oeste de Minas Gerais, composta por 35 municípios (Figura 1), situada entre as coordenadas geográficas $20^{\circ} 18^{\prime}$ e $18^{\circ} 28^{\prime}$ de latitude Sul e $51^{\circ} 12^{\prime}$ e 47을 $30^{\prime}$ de longitude a Oeste de Greenwich, ocupando uma área de 53.722,20 km² (IBGE, 2016).

$\begin{array}{llllll}\text { Caminhos de Geografia } & \text { Uberlândia - MG } & \text { v. 19, n. } 67 & \text { Set/2018 } & \text { p. 68-82 } & \text { Página } 69\end{array}$


A região do Triângulo Mineiro está inserida no Bioma Cerrado, abrangendo terras das bacias dos rios Paranaíba e Grande, na Região Hidrográfica do Paraná. Os solos, em sua grande maioria, são formados por Latossolos, bem profundos e bem drenados, com relevo plano a suave ondulado. Tratase de uma área de cobertura magmático-sedimentar pertencente à Bacia Sedimentar do Paraná, abrigando especialmente as unidades superiores correspondentes aos grupos São Bento e Bauru. Há, também, afloramentos de rochas proterozóicas e amplas coberturas terciárias da Formação Nova Ponte e unidades correlatas.

Figura 1: Mapa de localização dos municípios do Triângulo Mineiro, estado de Minas Gerais

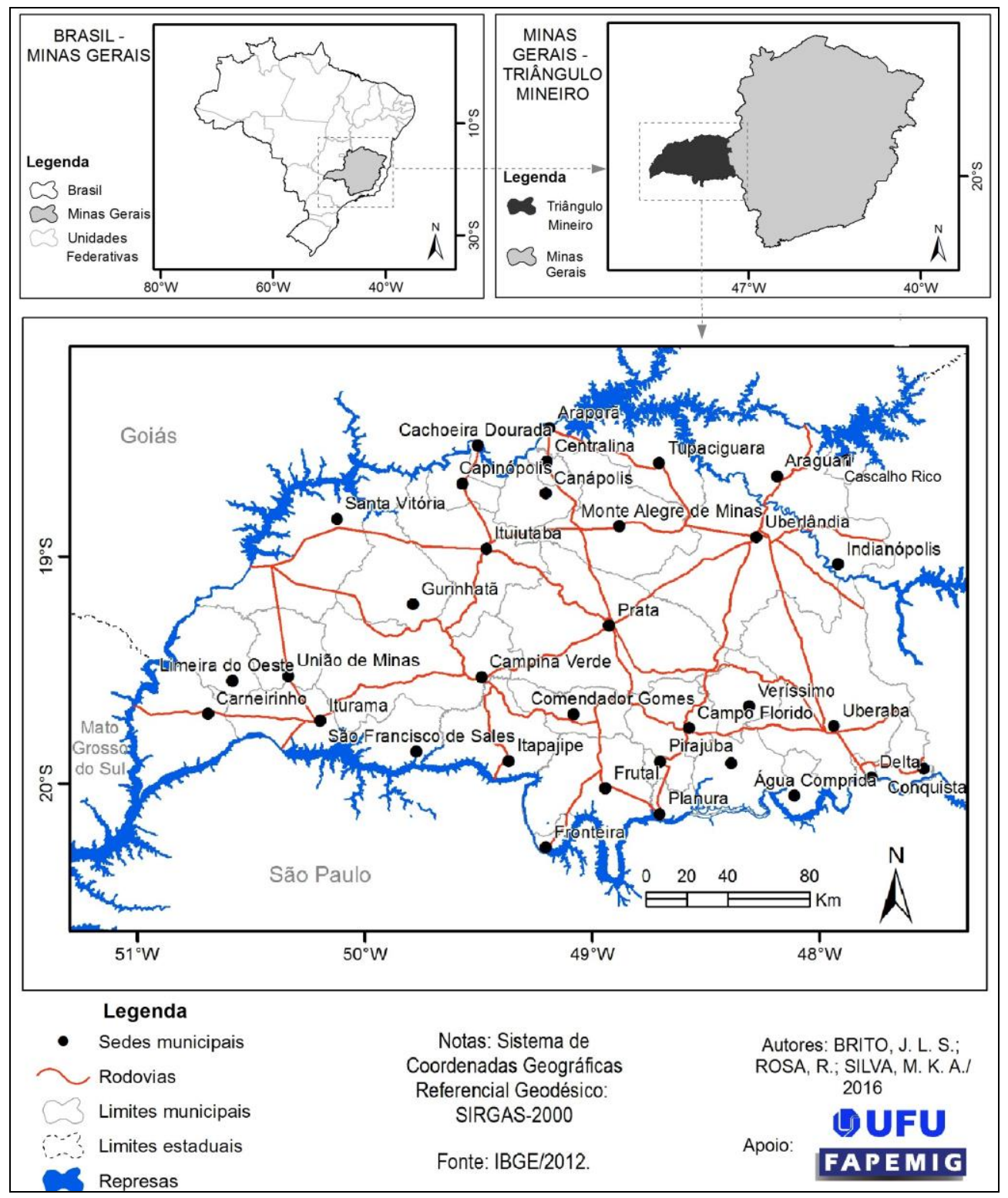

O Triângulo Mineiro está submetido a um regime climático tipicamente tropical, com duas estações bem definidas do ponto de vista pluviométrico: uma chuvosa, com reposição de água no solo e excedente hídrico e outra seca com deficiência hídrica. A precipitação média anual gira em torno dos $1.500 \mathrm{~mm}$. Observa-se no climograma da região (Figura 2) que o período de maior precipitação ocorre nos meses de outubro a março, concentrando, aproximadamente, $85 \%$ da chuva total anual (MENDES SILVA e FERREIRA, 2015). O mês mais seco do ano é julho com, aproximadamente, $8 \mathrm{~mm}$ precipitados e o mês mais chuvoso é janeiro com cerca de $260 \mathrm{~mm}$. A temperatura da região possui uma média mensal que varia entre $21^{\circ} \mathrm{C}$, nos meses de junho e julho, e $26^{\circ} \mathrm{C}$, no mês de outubro.

\begin{tabular}{lllllll}
\hline Caminhos de Geografia & Uberlândia - MG & v. 19, n. 67 & Set/2018 & p. 68-82 & Página 70
\end{tabular}


Figura 2: Climograma do Triângulo Mineiro

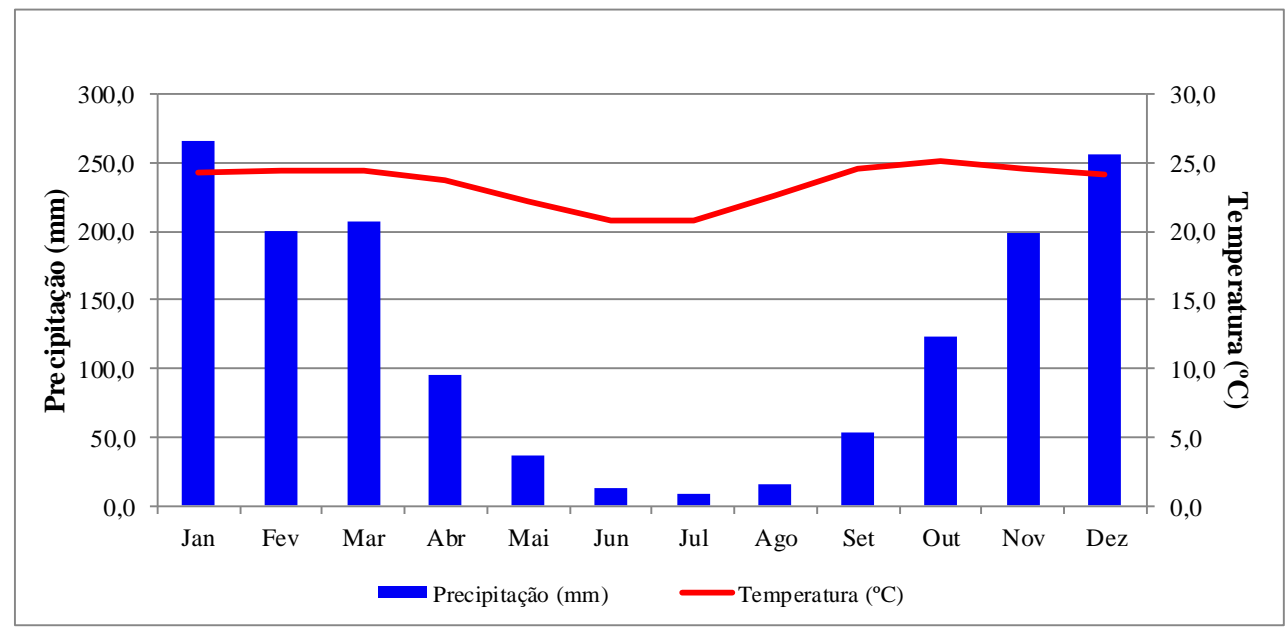

Fonte de dados de Precipitação: ANA,(2015) e de Temperatura: IINMET (1992)

\section{MAPEAMENTO DAS ÁREAS OCUPADAS COM PASTAGEM NO TRIÂNGULO MINEIRO}

Para o mapeamento da pastagem no Triângulo Mineiro foram utilizadas as imagens do sensor $O L I$, do satélite Landsat-8, bandas 3, 4 e 5, resolução espacial de 30 metros, cenas das órbitas 220 a 222 e pontos 073 e 074, do mês de setembro de 2015 (Figura 3). Essas imagens foram obtidas da interface earth explorer de busca e acesso às imagens do site do Instituto Nacional de Pesquisas Espaciais (INPE).

Figura 3: Cenas das imagens OLI/Landsat-8 utilizadas no mapeamento das áreas ocupadas com pastagens no Triângulo Mineiro, oeste do estado de Minas Gerais

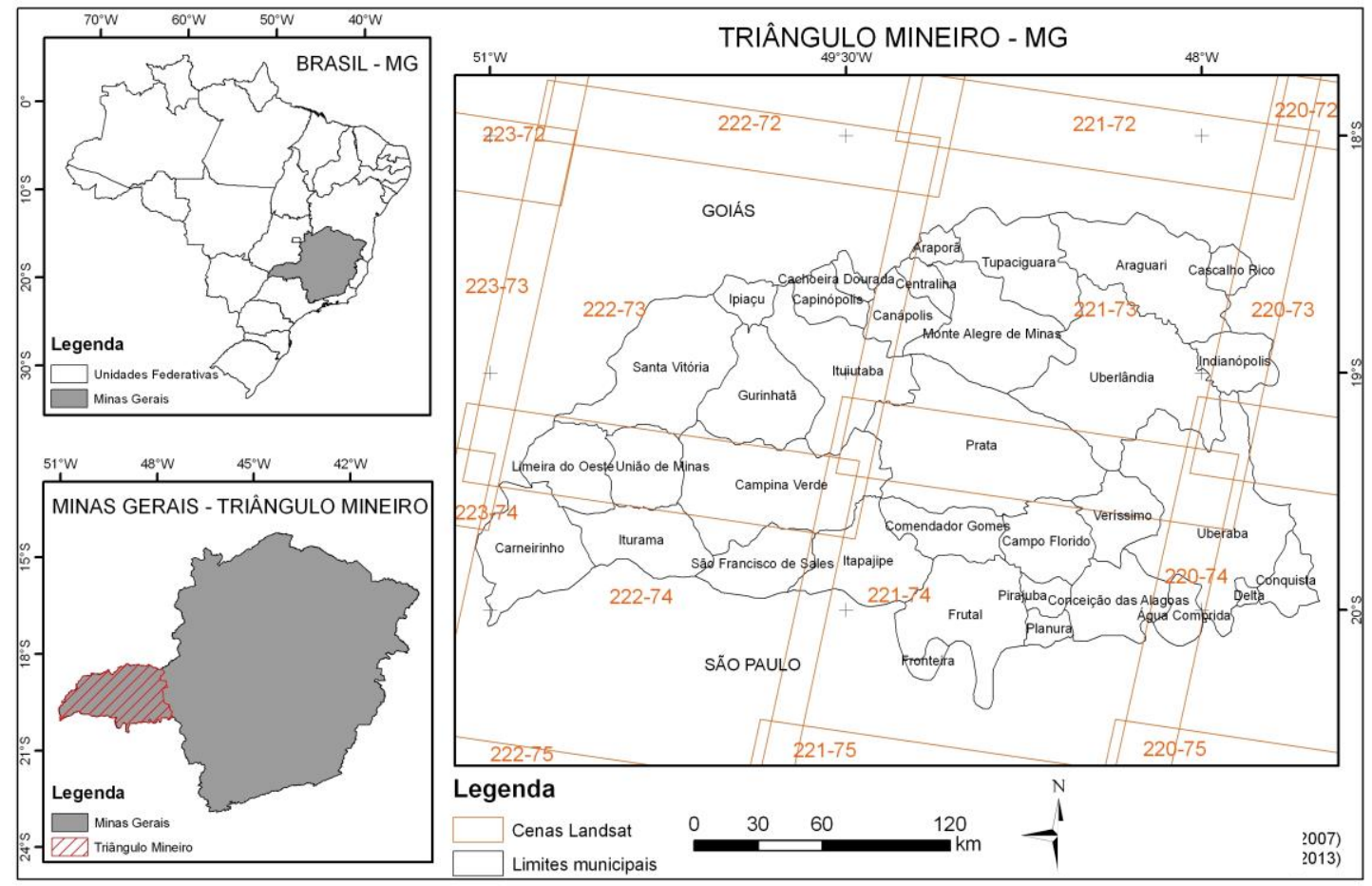

Foram consideradas, no presente trabalho, quatro tipos de pastagens (Tabela 1), definidas em função dos níveis de degradação, adaptados de Spain e Gualdrón (1988) e do projeto "Estado da arte das pastagens de Minas Gerais" (BRASIL, 2015).

$\begin{array}{llllll}\text { Caminhos de Geografia } & \text { Uberlândia - MG } & \text { v. 19, n. } 67 & \text { Set/2018 } & \text { p. 68-82 } & \text { Página } 71\end{array}$


Tabela 1: Fases de degradação de pastagens, segundo os parâmetros limitantes e nível de degradação

\begin{tabular}{cc}
\hline Níveis de degradação & Parâmetros Limitantes \\
\hline Não degradada & Pastagens melhoradas com bom vigor e boa qualidade \\
\hline Levemente degradada & Baixo vigor, qualidade e baixa população \\
\hline $\begin{array}{c}\text { Moderadamente } \\
\text { degradada }\end{array}$ & $\begin{array}{c}\text { Baixo vigor, qualidade e baixa população, associado com a presença de plantas } \\
\text { invasoras e/ou cupins }\end{array}$ \\
\hline $\begin{array}{c}\text { Fortemente degradada } \\
\text { Baixo vigor, qualidade e baixa população, associado com a presença de plantas } \\
\text { invasoras, cupins e solo descoberto }\end{array}$ \\
\hline
\end{tabular}

Fonte: Adaptado de Spain e Gualdrón (1988) e Brasil (2015)

Para a obtenção do mapa de pastagens, foram utilizados os seguintes procedimentos técnicos:

- Elaboração da base cartográfica do Triângulo Mineiro, a partir das cartas topográficas do IBGE, na escala 1:250.000, contendo a rede viária, a hidrografia, o limite e a sede dos municípios;

- Extração dos polígonos de pastagens do arquivo shapefile, do projeto TerraClass do Bioma Cerrado (Figura 4), correspondente a área do Triângulo Mineiro (ALMEIDA et al., 2016);

- Processamento digital das imagens OLI/Landsat-8 no software ENVI;

- Atualização e edição dos polígonos de pastagens da área do bioma Cerrado e delimitação dos polígonos de pastagens do Bioma Mata Atlântica, em tela do computador, na composição colorida 5R4G3B, considerando quatro classes de pastagens (Tabela 1), que apresentavam elementos distintos na chave de interpretação (Tabela 2);

- Trabalho de campo para verificação da precisão do mapeamento;

- Elaboração do mapa final de áreas ocupadas com pastagens e cálculo de áreas.

Figura 4: Áreas ocupadas pelos biomas Cerrado e Mata Atlântica no Triângulo Mineiro, oeste do estado de Minas Gerais.

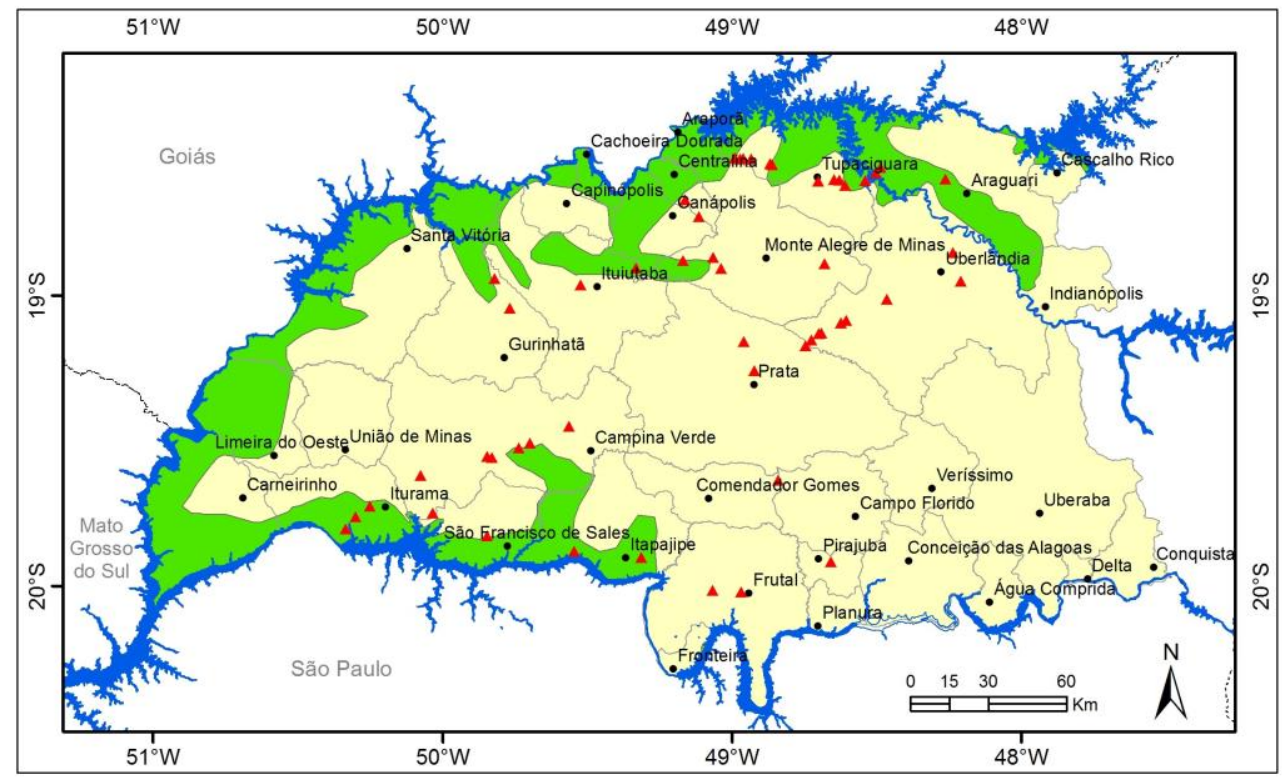

\begin{tabular}{|c|c|c|}
\hline Legenda & & Apoio: \\
\hline - Sedes municipais & - Locais visitados em campo & (L)UFU FAPEMIG \\
\hline 3 Limites municipais & Represas & \\
\hline $\begin{array}{l}\text { Notas: Sistema de Coordenadas Geográficas } \\
\text { Referencial Geodésico: SIRGAS-2000 }\end{array}$ & $\begin{array}{l}\text { Fonte: IBGE/2012; } \\
\text { Trabalho de campo/2016. }\end{array}$ & 2016 \\
\hline
\end{tabular}

Fonte: Adaptado de IBGE (2004). 
Tabela 2: Exemplo de chave de interpretação utilizada para a edição em tela do computador dos polígonos de pastagem, de acordo com a qualidade da pastagem na imagem OLI/Landsat8, composição colorida 5R4G3B, de outubro de 2015

\begin{tabular}{|c|c|c|c|}
\hline $\begin{array}{l}\text { Tipo de } \\
\text { pastagem }\end{array}$ & $\begin{array}{l}\text { Padrão característico de } \\
\text { interpretação }\end{array}$ & $\begin{array}{l}\text { Exemplo na } \\
\text { imagem }\end{array}$ & Foto \\
\hline Não degradada & $\begin{array}{l}\text { Padrão de cor: Vermelho com } \\
\text { textura média e forma geométrica } \\
\text { regular. }\end{array}$ & & \\
\hline $\begin{array}{l}\text { Levemente } \\
\text { degradada }\end{array}$ & $\begin{array}{l}\text { Padrão de cor: Vermelho } \\
\text { esverdeado com textura média e } \\
\text { forma geométrica regular }\end{array}$ & & \\
\hline $\begin{array}{l}\text { Modera-damente } \\
\text { degradada }\end{array}$ & $\begin{array}{l}\text { Padrão de cor: verde com textura } \\
\text { média e forma geométrica regular }\end{array}$ & & \\
\hline $\begin{array}{l}\text { Fortemente } \\
\text { degradada }\end{array}$ & $\begin{array}{l}\text { Padrão de cor: ciano com textura } \\
\text { média e forma geométrica regular. }\end{array}$ & & \\
\hline
\end{tabular}

\section{AVALIAÇÃO DA QUALIDADE DAS PASTAGENS DO TRIÂNGULO MINEIRO}

A avaliação da qualidade das pastagens foi obtida a partir dos trabalhos de campo (Figura 5) e do índice de vegetação EVI2, calculado a partir das imagens do satélite OLI/Landsat-8 de abril e maio de 2016, obtidas da interface Earth Explorer de busca e acesso às imagens do Serviço Geológico dos Estados Unidos (USGS). Para a correção radiométrica das bandas 3, 4 e 5 do sensor $O L /$ do satélite Landsat-8, os valores de Número Digital (ND) foram convertidos em valores de reflectância, utilizando os coeficientes radiométricos fornecidos no arquivo de metadados das imagens, de acordo com os parâmetros disponíveis no sítio da UNITED STATES GEOLOGICAL SURVEY (USGS), acesso em agosto de 2016.

A reflectância planetária do topo da atmosfera $\left(\rho \lambda^{\prime}\right)$ foi calculada com a Equação 1.

$$
\mathrm{p} \lambda^{0}=\mathrm{Mp} * \mathrm{Qcal}+A_{\mathrm{p}}
$$

Onde, $\mathrm{Mp}$ é o fator multiplicativo de reescalonamento para cada banda, disponível no metadados da imagem, $Q_{\text {cal }}$ é o ND para cada pixel e $A_{p}$ é o fator aditivo de reescalonamento para cada banda que é obtido no metadados da imagem.

Como a reflectância planetária no topo da atmosfera não apresenta correção para o ângulo solar foi necessário corrigi-la em função do ângulo solar e da distância astronômica Terra-Sol através da Equação 2.

$$
\mathrm{p} \lambda=\frac{\mathrm{p} \lambda^{\circ}}{\operatorname{sen}(\mathrm{\theta SE})}
$$


Onde $\theta_{\mathrm{SE}}$ corresponde ao ângulo de elevação solar, contido no arquivo de metadados.

Para o cálculo do índice de vegetação EVI2, utilizou-se a equação 3, proposta por Jiang et al., (2008):

$$
\left.\mathrm{EVI} 2=\left(2,5\left(\rho_{\text {nir }}-\rho_{\text {red }}\right)\right) /\left(\rho_{\text {nir }}+2,4 \rho_{\text {red }}+1\right)\right)
$$

Onde $\rho_{r ø d}$ é a reflectância na banda do vermelho (Banda 4 do sensor OLI/Landsat8) e $\rho_{\text {nir }}$ é a banda do infravermelho próximo (Banda 5 do sensor OLI/Landsat8) .

Figura 5: Localização e classificaçao das áreas de pastagens visitadas em campo

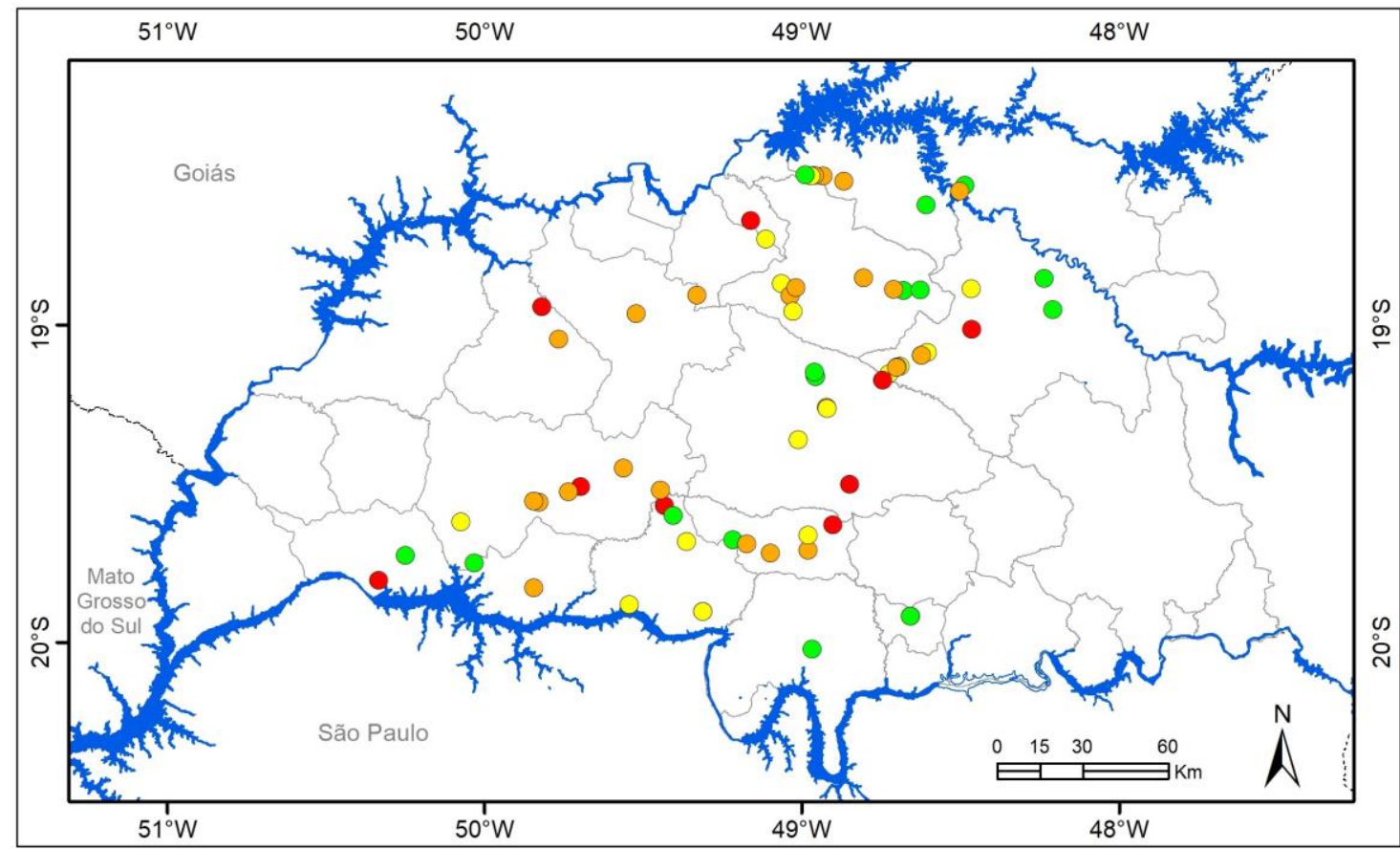

\begin{tabular}{|l} 
Nível de degradação das pastagens \\
Não degradada \\
Levemente degradada \\
Moderadamente degradada
\end{tabular}

Para cada imagem EVI2 foi calculada a média dos valores inseridos em cada um dos polígonos de pastagem visitados no campo. Esses valores foram então correlacionados com o tipo de pastagem definido em campo para obtenção dos intervalos de EVI2 para os quatro níveis de degradação das pastagens descritos na Tabela 2.

\section{RESULTADOS E DISCUSSÕES}

\section{MAPEAMENTO DAS ÁREAS OCUPADAS COM PASTAGEM NO TRIÂNGULO MINEIRO}

A Figura 6 apresenta o mapa de distribuição das pastagens no Triângulo Mineiro, em 2015. A partir da verificação de campo, foi possível confirmar que, das cinquenta e quatro amostras

$\begin{array}{llllll}\text { Caminhos de Geografia } & \text { Uberlândia - MG } & \text { v. 19, n. } 67 & \text { Set/2018 } & \text { p. 68-82 } & \text { Página } 74\end{array}$


identificadas como pastagens, dez não foram mapeadas, obtendo assim, um grau de concordância do mapeamento de $81 \%$.

Figura 6: Distribuição espacial das áreas ocupadas com pastagens, em 2015, nos municípios do Triângulo Mineiro, estado de Minas Gerais

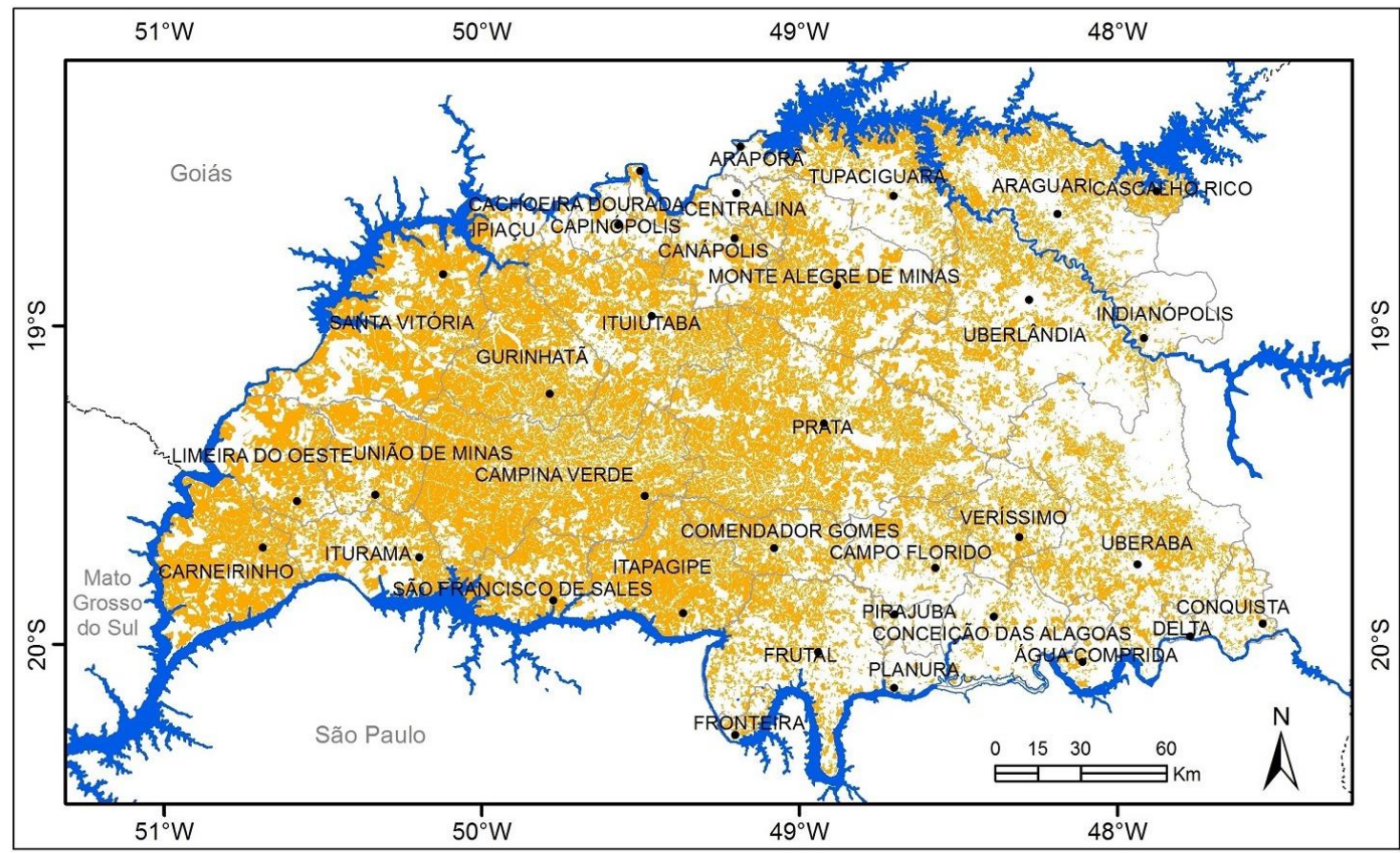

Legenda
Sedes municipais
$\begin{aligned} & \text { Notas: Sistema de Coordenadas Geográficas } \quad \text { Fonte: IBGE/2012; TERRACLASS - MMA/201 } \\ & \text { Referencial Geodésico: SIRGAS-2000 }\end{aligned}$

A Tabela 3 indica o percentual de áreas ocupadas com pastagens nos municípios do Triângulo Mineiro. A área total ocupada é de $24.184,65 \mathrm{~km}^{2}$, correspondendo a $45,02 \%$ das terras do Triângulo Mineiro. O município com a maior área ocupada com pastagem é Campina Verde $(69,7 \%)$ e o município com a menor área ocupada com pastagens é Planura $(9,1 \%)$.

A Figura 7 mostra a estratificação da área de estudo em função do percentual de área dos municípios ocupada com pastagem no ano de 2015, indicando que os municípios situados no oeste do Triângulo mineiro ainda utilizam 60 a $70 \%$ de suas terras com pastagens. Já os municípios situados na porção Sudeste da região (Delta, Uberaba, Planura, Conquista e Água Comprida, Frutal e Pirajuba) utilizam menos de $30 \%$ de suas terras com pastagens. Esses municípios apresentam um uso intenso com a cultura de cana-de açúcar. 
Mapeamento e avaliação da qualidade das pastagens cultivadas no Triângulo Mineiro a partir de imagens OLI/Landsat-8
Jorge Luís Silva Brito

Roberto Rosa

Vanderlei de Oliveira Ferreira

Eleusa Fátima de Lima

Mirna Karla Amorim da Silva

Tabela 3: Cálculo da área ocupada pelas pastagens, no ano de 2015 nos municípios do Triângulo Mineiro, estado de Minas Gerais.

\begin{tabular}{|c|c|c|c|}
\hline \multirow[t]{2}{*}{ MUNICÍPIOS } & \multirow{2}{*}{$\begin{array}{l}\text { ÁREA DO } \\
\text { MUNICÍPIO } \\
\left(\mathbf{k m}^{2}\right)\end{array}$} & \multicolumn{2}{|c|}{$\begin{array}{l}\text { ÁREA DO MUNICÍPIO OCUPADA COM } \\
\text { PASTAGEM }\end{array}$} \\
\hline & & $\left(\mathbf{k m}^{2}\right)$ & $\%$ \\
\hline Água comprida & 492,22 & 89,17 & 18,12 \\
\hline Araguari & $2.729,51$ & $1.059,06$ & 38,8 \\
\hline Araporã & 295,84 & 61,48 & 20,78 \\
\hline Cachoeira Dourada & 200,93 & 63,6 & 31,65 \\
\hline Campina Verde & $3.650,75$ & $2.542,95$ & 69,66 \\
\hline Campo Florido & $1.264,25$ & 386,46 & 30,57 \\
\hline Canápolis & 839,74 & 306,57 & 36,51 \\
\hline Capinópolis & 620,72 & 160,19 & 25,81 \\
\hline Carneirinho & $2.063,32$ & $1.325,57$ & 64,24 \\
\hline Cascalho Rico & 367,31 & 197,41 & 53,74 \\
\hline Centralina & 327,19 & 84,96 & 25,97 \\
\hline Comendador Gomes & $1.041,05$ & 533,77 & 51,27 \\
\hline Conceição das Alagoas & $1.340,25$ & 205,9 & 15,36 \\
\hline Conquista & 618,36 & 135,56 & 21,92 \\
\hline Delta & 102,84 & 14,71 & 14,3 \\
\hline Fronteira & 199,99 & 69,32 & 34,66 \\
\hline Frutal & $2.426,97$ & 765,2 & 31,53 \\
\hline Gurinhatã & $1.849,14$ & 1259 & 68,09 \\
\hline Indianópolis & 830,03 & 107,63 & 12,97 \\
\hline Ipiaçu & 466,02 & 169,83 & 36,44 \\
\hline Itapagipe & $1.802,44$ & $1.138,97$ & 63,19 \\
\hline Ituiutaba & $2.598,05$ & $1.500,27$ & 57,75 \\
\hline Iturama & $1.404,66$ & 614,89 & 43,78 \\
\hline Limeira do Oeste & $1.319,04$ & 718,38 & 54,46 \\
\hline Monte Alegre de Minas & $2.595,96$ & $1.169,86$ & 45,06 \\
\hline Pirajuba & 337,98 & 33,85 & 10,02 \\
\hline Planura & 317,52 & 28,92 & 9,11 \\
\hline Prata & $4.847,54$ & $2.799,19$ & 57,74 \\
\hline Santa Vitória & $3.001,36$ & $1.666,33$ & 55,52 \\
\hline São Francisco de Sales & $1.128,86$ & 627,51 & 55,59 \\
\hline Tupaciguara & $1.823,96$ & 638,27 & 34,99 \\
\hline Uberaba & $4.523,96$ & $1.247,13$ & 27,57 \\
\hline Uberlândia & $4.115,21$ & $1.330,77$ & 32,34 \\
\hline União de minas & $1.147,41$ & 733,14 & 63,9 \\
\hline Veríssimo & $1.031,82$ & 398,8 & 38,65 \\
\hline Total & $53.722,20$ & $24.184,65$ & 45,02 \\
\hline
\end{tabular}


Figura 7: Distribuição espacial das classes de área ocupada com pastagens, em 2015, nos municípios do Triângulo mineiro, estado de Minas Gerais

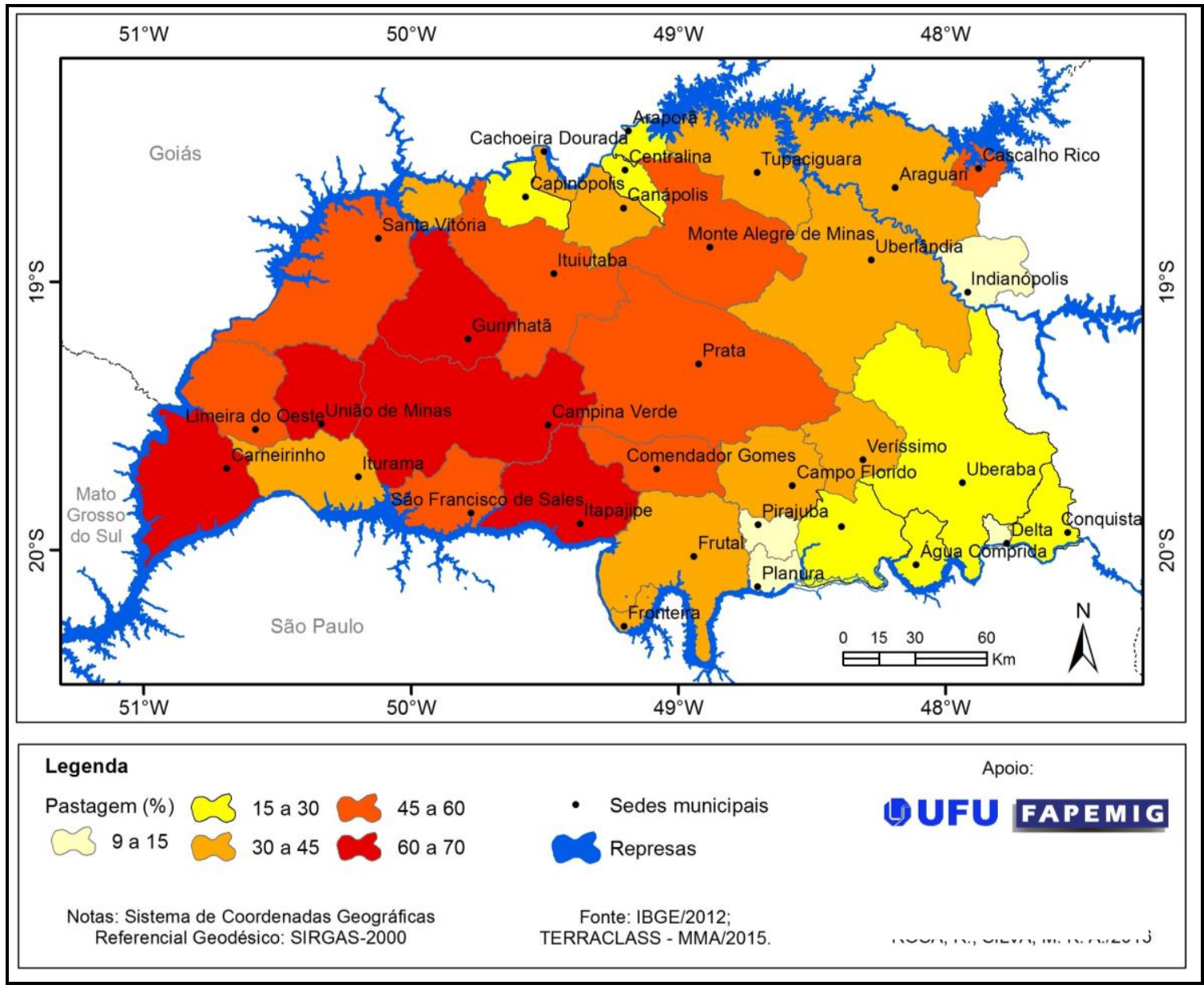

\section{AVALIAÇÃO DA QUALIDADE DAS PASTAGENS NO TRIÂNGULO MINEIRO}

Os valores médios do índice de vegetação EVI2 dos polígonos visitados em campo e classificados de acordo com o nível de degradação, obtidos das imagens OLI/Landsat nos meses de abril e maio de 2016, são apresentados na Tabela 4.

A Figura 8 indica que houve uma forte correlação $(R=0,82)$ entre o nível de degradação das pastagens e os valores de EVI2, evidenciando assim que, quanto menor o valor do EVI2, maior será o grau de degradação da pastagem. Esses resultados indicam que o EVI2 pode ser utilizado como um indicador do nível de degradação das pastagens. A partir disso, definiu-se quatro intervalos de classe de EVI2 para os quatro níveis de degradação das pastagens (Tabela 5). 
Tabela 4: Classificação das pastagens de acordo com o nível de degradação e valores vegetação EVI2 dos polígonos visitados em campo, obtidos das imagens OLI/Landsat dos meses de abril e maio de 2016

\begin{tabular}{|c|c|c|c|c|c|c|c|c|}
\hline \multicolumn{3}{|c|}{$16 / 11 / 2016$} & \multicolumn{3}{|c|}{$26 / 05 / 2017$} & \multicolumn{3}{|c|}{$03 / 06 / 2017$} \\
\hline AMOSTRA & TIPO* & EVI2 & AMOSTRA & TIPO* & EVI2 & AMOSTRA & TIPO* & EVI2 \\
\hline 1 & 3 & 0,30 & 35 & 1 & 0,37 & 57 & 1 & 0,31 \\
\hline 5 & 3 & 0,36 & 37 & 1 & 0,41 & 68 & 1 & 0,28 \\
\hline 6 & 1 & 0,37 & 38 & 3 & 0,36 & 59 & 1 & 0,38 \\
\hline 7 & 3 & 0,19 & 45 & 3 & 0,28 & 60 & 4 & 0,15 \\
\hline 9 & 2 & 0,33 & 47 & 2 & 0,37 & 61 & 3 & 0,28 \\
\hline 10 & 2 & 0,33 & 48 & 3 & 0,29 & 62 & 1 & 0,41 \\
\hline 11 & 1 & 0,34 & 49 & 1 & 0,48 & 63 & 3 & 0,30 \\
\hline 12 & 1 & 0,37 & 50 & 3 & 0,16 & 64 & 3 & 0,24 \\
\hline 13 & 1 & 0,36 & 51 & 2 & 0,19 & 65 & 3 & 0,28 \\
\hline 14 & 2 & 0,34 & 52 & 3 & 0,22 & 66 & 4 & 0,07 \\
\hline 15 & 3 & 0,28 & 53 & 3 & 0,24 & 67 & 2 & 0,32 \\
\hline 18 & 3 & 0,22 & 54 & 2 & 0,34 & 68 & 2 & 0,32 \\
\hline 19 & 3 & 0,19 & 55 & 3 & 0,31 & 69 & 2 & 0,34 \\
\hline 20 & 1 & 0,36 & 56 & 1 & 0,19 & 70 & 4 & 0,08 \\
\hline 21 & 4 & 0,18 & & & & 71 & 4 & 0,16 \\
\hline 24 & 2 & 0,17 & & & & 72 & 2 & 0,35 \\
\hline 25 & 3 & 0,19 & & & & 73 & 3 & 0,27 \\
\hline 27 & 2 & 0,33 & & & & 74 & 2 & 0,33 \\
\hline 28 & 2 & 0,35 & & & & & & \\
\hline 31 & 1 & 0,41 & & & & & & \\
\hline 32 & 4 & 0,17 & & & & & & \\
\hline 17 & 2 & 0,36 & & & & & & \\
\hline 33 & 3 & 0,28 & & & & & & \\
\hline 34 & 1 & 0,57 & & & & & & \\
\hline 40 & 4 & 0,16 & & & & & & \\
\hline
\end{tabular}

*Tipos de Pastagem: 1: Não degradada; 2: Levemente degradada; 3: Moderadamente degradada; 4: Fortemente degradada.

Figura 8: Regressão linear entre os níveis de degradação das pastagens e os valores médios de EVI2 dos polígonos de pastagem visitados em campo.

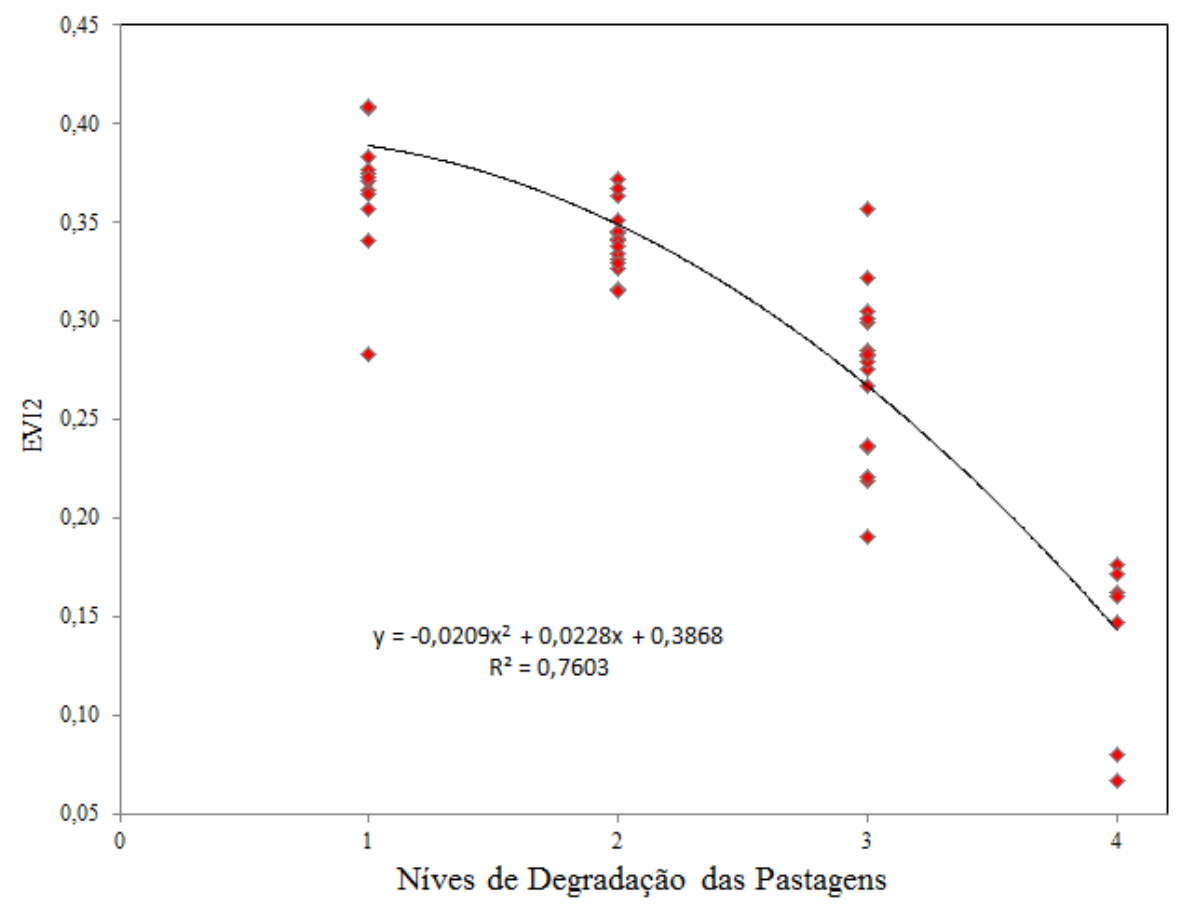


Tabela 5: Níveis de degradação das pastagens e intervalos de classes dos valores de EVI2 dos polígonos de pastagem visitados em campo

\begin{tabular}{c|c|c}
\hline Classe & Nível de Degradação & Valores de EVI2 \\
\hline \multirow{2}{*}{2} & Fortemente degradadas & $<0,18$ \\
\cline { 2 - 3 } 3 & Moderadamente degradadas & $0,18 \mathrm{a} 0,31$ \\
\cline { 2 - 3 } 4 & Levemente degradadas & $0,31 \mathrm{a} 0,37$ \\
\cline { 2 - 3 } & Não degradadas & $>0,37$ \\
\hline
\end{tabular}

A imagem contendo os valores de EVI2 para o Triângulo mineiro foi classificada de acordo com os intervalos de valores de EVI2 descritos na tabela 4, resultando assim, no mapa temático de níveis de degradação das pastagens (Figura 9). As pastagens moderadamente a fortemente degradadas estão concentradas principalmente nos municípios de Prata, Monte Alegre de Minas, Campo Florido e parte sudoeste de Uberlândia, onde predominam solos de textura arenosa. No entanto, as áreas de pastagens não degradadas a levemente degradadas ocorrem, principalmente, no município de Araguari, Uberaba, porção norte do município de Uberlândia, onde predominam os solos de textura argilosa.

Figura 9: Distribuição espacial dos tipos de pastagem do Triangulo Mineiro, classificadas de acordo com os valores do índice de vegetação EVI2 e o níveis de degradação

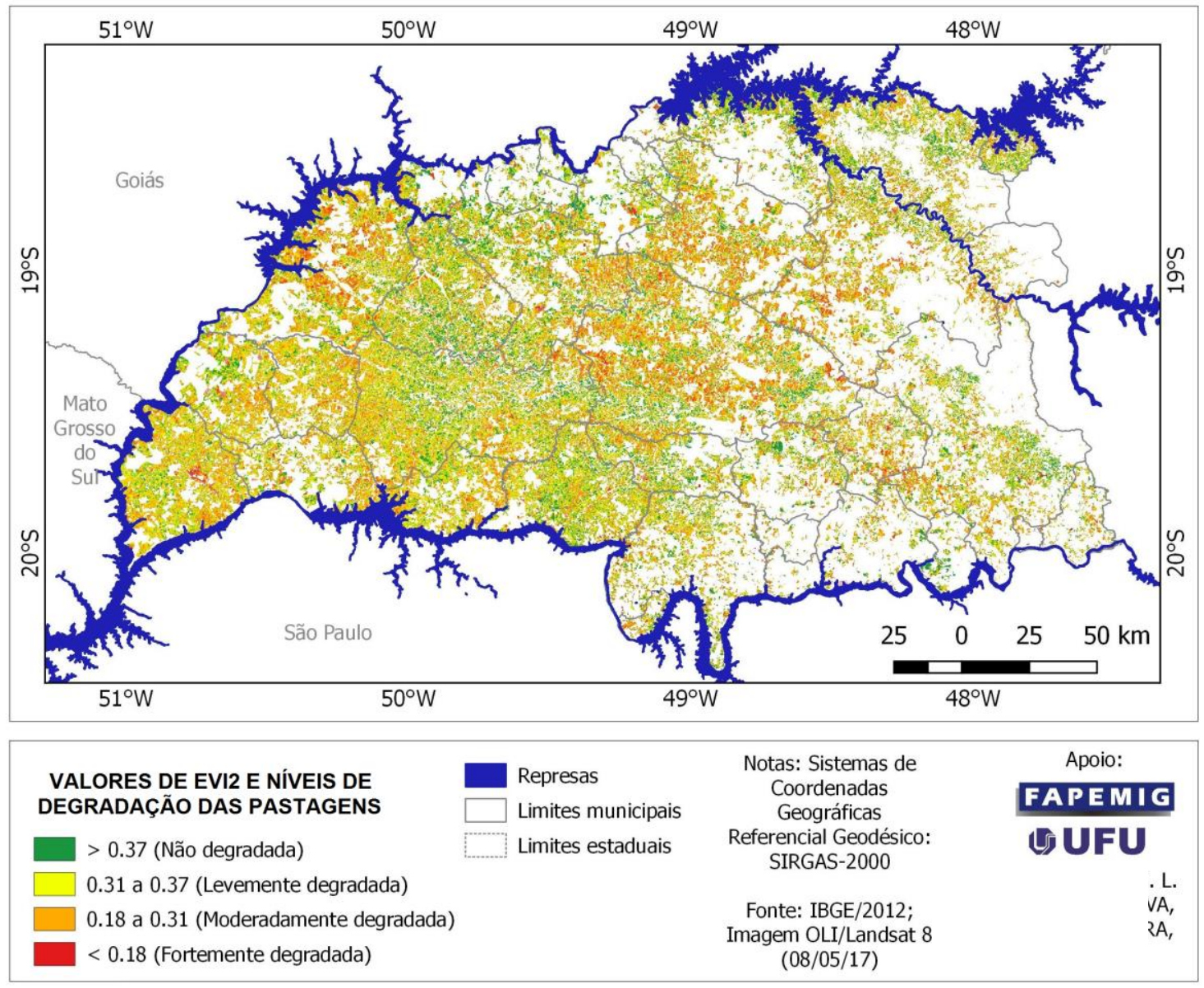


Os valores de área ocupada pelas casses de nível de degradação das pastagens são apresentados na Tabela 6. Esses resultados indicam que $30,78 \%$ pastagens do Triângulo Mineiro não estão degradadas e que $69,22 \%$ apresentam algum grau de degradação.

Tabela 6: Área ocupada por classe de nível de degradação das pastagens do Triângulo mineiro em 2016.

\begin{tabular}{c|r|r}
\hline \multirow{2}{*}{ Níveis de degradação da pastagem / Área } & \multicolumn{2}{|c}{ Area ocupada } \\
\cline { 2 - 3 } & $\mathbf{K m}^{\mathbf{2}}$ & $\mathbf{3}$ \\
\hline Não degradada & 7444,26 & 30,78 \\
\hline Levemente degradada & 8370,33 & 34,61 \\
\hline Moderadamente degradada & 5278,40 & 21,83 \\
\hline Fortemente degradada & 3091,65 & 12,78 \\
\hline Total & $\mathbf{2 4 . 1 8 4 , 6 5}$ & $\mathbf{1 0 0 , 0 0}$ \\
\hline
\end{tabular}

\section{CONSIDERAÇÕES FINAIS}

Os resultados do mapeamento indicaram que, em 2015, as áreas de pastagens ocuparam $24.184,65$ $\mathrm{km}^{2}$, das terras do Triângulo Mineiro, correspondendo a 45,0\% da área total, sendo que o município com a maior área ocupada com pastagem foi Campina Verde $(69,7 \%)$ e o município com a menor área ocupada com pastagens foi Planura $(9,1 \%)$. A metodologia utilizada mostrou-se satisfatória, pois produziu um mapa com uma confiabilidade de $81 \%$.

A estratificação da área de estudo em função do percentual de área dos municípios ocupada com pastagem no ano de 2015, indicam que os municípios situados no oeste do Triângulo mineiro ainda utilizam 60 a $70 \%$ de suas terras com pastagens. Já os municípios situados na porção Sudeste da região (Delta, Uberaba, Planura, Conquista e Água Comprida, Frutal e Pirajuba) utilizam menos de $30 \%$ de suas terras com pastagens. Esses municípios apresentam um uso intenso com a cultura de cana-de açúcar.

A classificação dos tipos de pastagem a partir do índice de vegetação EVI2, indicaram que 30,78\% das pastagens do Triângulo mineiro são de boa qualidade, portanto, não degradadas, enquanto $69,22 \%$ apresentam algum grau de degradação, sendo que $34,61 \%$ foram classificadas como levemente degradadas, $21,83 \%$ como moderadamente degradadas e $12,78 \%$ como fortemente degradadas.

A partir dos trabalhos de campo, verificou-se que áreas com nível de degradação moderado a forte estão concentradas principalmente nos municípios de Prata, Monte Alegre de Minas, Campo Florido e parte sudoeste de Uberlândia, onde predominam solos de textura arenosa. No entanto, as áreas de pastagens não degradadas a levemente degradadas ocorrem principalmente nos municípios de Araguari, Uberaba, porção norte do município de Uberlândia, onde predominam os solos de textura argilosa.

\section{AGRADECIMENTOS}

Á Fundação de Amparo à Pesquisa do Estado de Minas Gerais (FAPEMIG) pelo auxílio na Pesquisa através do projeto no CRA-APQ-01542-14. Ao Instituto de Geografia da Universidade Federal de Uberlândia pelo apoio de transporte para a realização dos trabalhos de campo, essenciais para a conclusão dessa pesquisa.

$\begin{array}{llllll}\text { Caminhos de Geografia } & \text { Uberlândia - MG } & \text { v. 19, n. } 67 & \text { Set/2018 } & \text { p. 68-82 } & \text { Página } 80\end{array}$




\section{REFERÊNCIAS}

ANA . Agência Nacional De Águas. Sistema de Informações Hidrológicas: Disponível em Hidroweb: http://hidroweb.ana.gov.br. Brasília, 2015.

ALMEIDA, C.A.; COUTINHO, A.C.; ESQUERDO, J.C.D.M.; ADAMI, M.; VENTURIERI, A.; DINIZ, C.G.; DESSAY, N.; DURIEUX, L.; GOMES, A.R. High spatial resolution land use and land cover mapping of the Brazilian Legal Amazon in 2008 using Landsat-5/TM and MODIS data. Acta Amazonica, Vol 46 (3) 2016: 291-302. https://doi.org/10.1590/1809-4392201505504

ANJOS, V.S.; SANO, E.E.; BEZERRA, H.S.; ROSA, R. Caracterização espectro-temporal de pastagens do Triângulo Mineiro utilizando dados MODIS EVI2 (2000-2010). Sociedade \& Natureza, v.25, n.1, p. 205-215, 2013. https://doi.org/10.1590/S1982-45132013000100016

BRASIL. Ministério da Agricultura, Pecuária e Abastecimento. Grupo Gestor do Plano Agricultura de Baixa Emissão de Carbono. Superintendência. Estado da Arte das Pastagens em Minas Gerais. Belo Horizonte, 2015. Disponível em: <http://www.sistemafaemg.org.br.

Acesso em 20 de janeiro de 2017.

BRITO, J.L.S.; PRUDENTE, T.D. Análise temporal do uso do solo e cobertura vegetal do município de Uberlândia-MG, utilizando imagens ETM+/Landsat 7. Sociedade \& Natureza, v. 17, n. 32, p. 37-46, 2005.

BRITO, J. L. S., REIS, L. N. G. Mapeamento das áreas de conversão do uso da terra para cana-deaçúcar na região do Triângulo mineiro/Alto Paranaíba-MG por meio de imagens TM/landsat.

Caminhos de Geografia, v.13, p.170 -186, 2012.

FERREIRA, L. G.; SANO, E. E.; FERNANDEZ, L.; ARAÚJO, F. M. Biophysical characteristics and fire occurrence of cultivated pastures in the Brazilian savanna observed by moderate resolution satellite data. International Journal of Remote Sensing, v. 34, n. 1, p. 154-167, 2013.

https://doi.org/10.1080/01431161.2012.712223

IBGE. Área territorial dos Municípios do Brasil. Disponível em: http://www.ibge.gov.br/home/ geociencias/areaterritorial/area.shtm. Acesso em: 03 nov. 2016.

IBGE. Instituto Brasileiro de Geografia e Estatística. Produção da Pecuária Municipal 2015. Rio de Janeiro: IBGE, v. 43, p. 49, 2015.

IBGE. Mapa de biomas do Brasil. Escala 1:5.000.000. Rio de Janeiro: IBGE, 2004. Disponível em: <www.mapas.ibge.gov.br/biomas2/ viewer.htm>. Acesso em: 10 set. 2016.

INMET. Instituto Nacional de Meteorologia do Brasil. Normais Climatológicas (1961/1990). Brasília, 1992.

INPE. Instituto Nacional de Pesquisas Espaciais. Imagens do sensor OLI do satélite Landsat8.

Disponível em: <www.dgi.inpe.br/catalogo>. Acesso em: 10 de novembro de 2015.

INPE. Instituto Nacional de Pesquisas Espaciais. Projeto TerraClass Cerrado

Mapeamento do Uso e Cobertura Vegetal do Cerrado Disponível em:

<http://www.dpi.inpe.br/tccerrado/download.php>. Acesso em 10 de novembro de 2015.

JIANG, Z.; HUETE, A. R.; DIDAN, K.; MIURA, T. Development of a two-band Enhanced Vegetation Index without a blue band, Remote Sensing of Environment, 112(10), p 3833-3845. 2008. https://doi.org/10.1016/..rse.2008.06.006

MACEDO, M.C.M.; ZIMMER, A.H. Sistema pasto-lavoura e seus efeitos na produtividade agropecuária. In: FAVORETTO, V.; RODRIQUES, L.R.A.; REIS, R.A. (eds.). Simpósio sobre ecossistemas de pastagens, 2, 1993, Jaboticabal. Anais... Jaboticabal: FUNEP, UNESP, 1993. p.216-245.

MENDES SILVA, M; FERREIRA, V. O. Pluviometria e balanço hídrico da bacia do rio Paranaíba. Revista Brasileira de Geografia Física, v. 8, p. 1335-1346, 2015.

PERON, A. J.; EVANGELISTA, A. R. Degradação de pastagens em regiões de Cerrado. Ciência e Agrotecnologia, v. 28, n. 3, p. 655-661, 2004. https://doi.org/10.1590/S1413-70542004000300023 
SANO, E. E.; ROSA, R.; BRITO, J. L. S.; FERREIRA, L. G. Land cover mapping of the tropical savanna region in Brazil. Environmental Monitoring and Assessment, v. 166, p. 113-124, 2010. https://doi.org/10.1007/s10661-009-0988-4

SPAIN, J. M.; GUALDRÓN, R. Degradación y rehabilitación de pasturas. In: IV reunión del comité asesor de la riept. Memórias. Red internacional de evaluación de pastos tropicales. Veracruz, México 1988. Ciat. p. 269-283.

UNITED STATES GEOLOGICAL SURVEY (USGS). Landsat Project Description. Disponível em: $<$ http://landsat.usgs.gov/about_project_descriptions.php>. Acesso em agosto de 2016.

Recebido em: 27/09/2017

Aceito para publicação em: 25/09/2018 